\title{
A look at autoimmunity and inflammation in the eye
}

\author{
Rachel R. Caspi
}

Laboratory of Immunology, National Eye Institute, NIH, Bethesda, Maryland, USA.

\begin{abstract}
Autoimmune and inflammatory uveitis are a group of potentially blinding intraocular inflammatory diseases that arise without a known infectious trigger and are often associated with immunological responses to unique retinal proteins. In the United States, about $10 \%$ of the cases of severe visual handicap are attributed to this group of disorders. As I discuss here, experimental models of ocular autoimmunity targeting retinal proteins have brought about a better understanding of the basic immunological mechanisms involved in the pathogenesis of uveitis and are serving as templates for the development of novel therapies.
\end{abstract}

\section{Introduction}

The structure of the eye is highly organized and complex (Figure 1), reflecting the high degree of specialization that is required to support its function. The integrity and transparency of the ocular media (aqueous, lens, and vitreous), which refract, transmit, and sense light, are critical to optimal visual function. Any distortion of the visual axis - from the cornea through the anterior chamber, lens, and vitreous body to the retina (Figure 1) - by inflammatory processes within the eye can adversely affect vision. Uveitis or uveoretinitis is a general term referring to inflammation of the retina and uvea (the pigmented vascular coat of the eyeball, consisting of the choroid, ciliary body, and iris). Uveitis is categorized on an anatomical basis as anterior, intermediate, or posterior, or as panuveitis if it involves both the anterior and posterior parts of the eye. Noninfectious uveitis is believed to be autoimmune or immune-mediated (1). Although the distinction between autoimmune and immune-mediated causality can be blurry, the former is generally believed to be driven by aberrant immune recognition of self, whereas the latter is primarily an innate inflammatory reaction triggered by environmental (microbial) or autologous (tissue damage) "danger" signals. Uveitis, especially if untreated, can result in significant visual deficit and blindness. In the United States alone, uveitic diseases of noninfectious origin have an incidence of 52.4 per 100,000 and a prevalence of 115.3 per 100,000 , and are believed to account for about $10 \%$ of legal blindness (2).

Some uveitic diseases are confined to the eye, such as sympathetic ophthalmia and birdshot retinochoroidopathy. Others are part of a generalized systemic syndrome in which the eye is one of several organs involved. Examples include anterior uveitis associated with juvenile idiopathic arthritis or ankylosing spondylitis, posterior uveitis in Behçet disease (which also involves skin and mucosal tissues), Vogt-Koyanagi-Harada (VKH) disease (which also targets melanocytes of the skin), and ocular sarcoidosis (part of systemic sarcoidosis, a multisystem inflammatory granulomatous disease that also targets the lymph nodes, lungs, and skin) $(1,3)$ (Table 1). However, many cases of noninfectious uveitis do not fall under a defined classification and are referred to as "idiopathic." Patients with noninfectious uveitis frequently exhibit immune responses targeted to ocular antigens such as uveal melanin and proteins involved in its metabolism, retinal arrestin (for-

Conflict of interest: The author has declared that no conflict of interest exists. Citation for this article: J Clin Invest. 2010;120(9):3073-3083. doi:10.1172/JCI42440. merly known as the 48-kDa retinal soluble antigen [S-Ag]), interphotoreceptor retinoid-binding protein (IRBP), and recoverin $(4,5)$. Although it is unclear whether these immune responses represent the etiological cause or an epiphenomenon of autoimmunization to the products of tissue breakdown (especially in diseases where the initial trigger may be microbial; see Table 1), they are believed to fuel progression of the disease. Diseases in this group tend to have strong MHC associations (6), which is believed to indicate an autoimmune etiology, because MHC molecules select and present antigens for recognition by $\mathrm{T}$ cells.

While the transparency of ocular media facilitates observation of the disease process using noninvasive techniques, the delicate nature of ocular tissues makes it difficult to obtain tissue specimens. This limitation has greatly hampered studies of the mechanisms involved in uveitic disease. However, over the past several decades, animal models of autoimmune uveitis directed at eye-specific antigens have been developed and have allowed researchers to approach the study of the basic mechanisms driving ocular autoimmunity at a whole new level (reviewed in refs. $7,8)$. In this Review, I attempt to put what we have learned from these models in perspective and discuss what they can teach us about human disease.

\section{The immune system and the eye: a tenuous relationship}

The eye has evolved to limit intraocular inflammation so as to protect the delicate visual elements from damage that would be detrimental to visual acuity and therefore survival (9). This ability of the eye to curb and control immune responses is known as ocular immune privilege. This term was initially coined by Peter Medawar in the middle of the 20th century, essentially to describe his observation that tissue grafts from non-genetically identical animals placed in the eye were not rejected (10). It was subsequently found by many groups to be a highly complex phenomenon, resulting from the combined effects of efficient separation of the eye from the immune system by a blood-retinal barrier, local inhibition of immune responses by the unique intraocular microenvironment, and systemic induction of immunosuppressive regulatory $\mathrm{T}$ cells by eye-specific mechanisms. Ocular fluids contain the immunoinhibitory cytokine TGF- $\beta$ and other immunoinhibitory substances and are able to curb the destructive activities of inflammatory cells of both the innate and adaptive immune systems (9). However, while it is generally accepted that immune privilege protects the eye from day-to-day inflammatory insults and contributes to the 


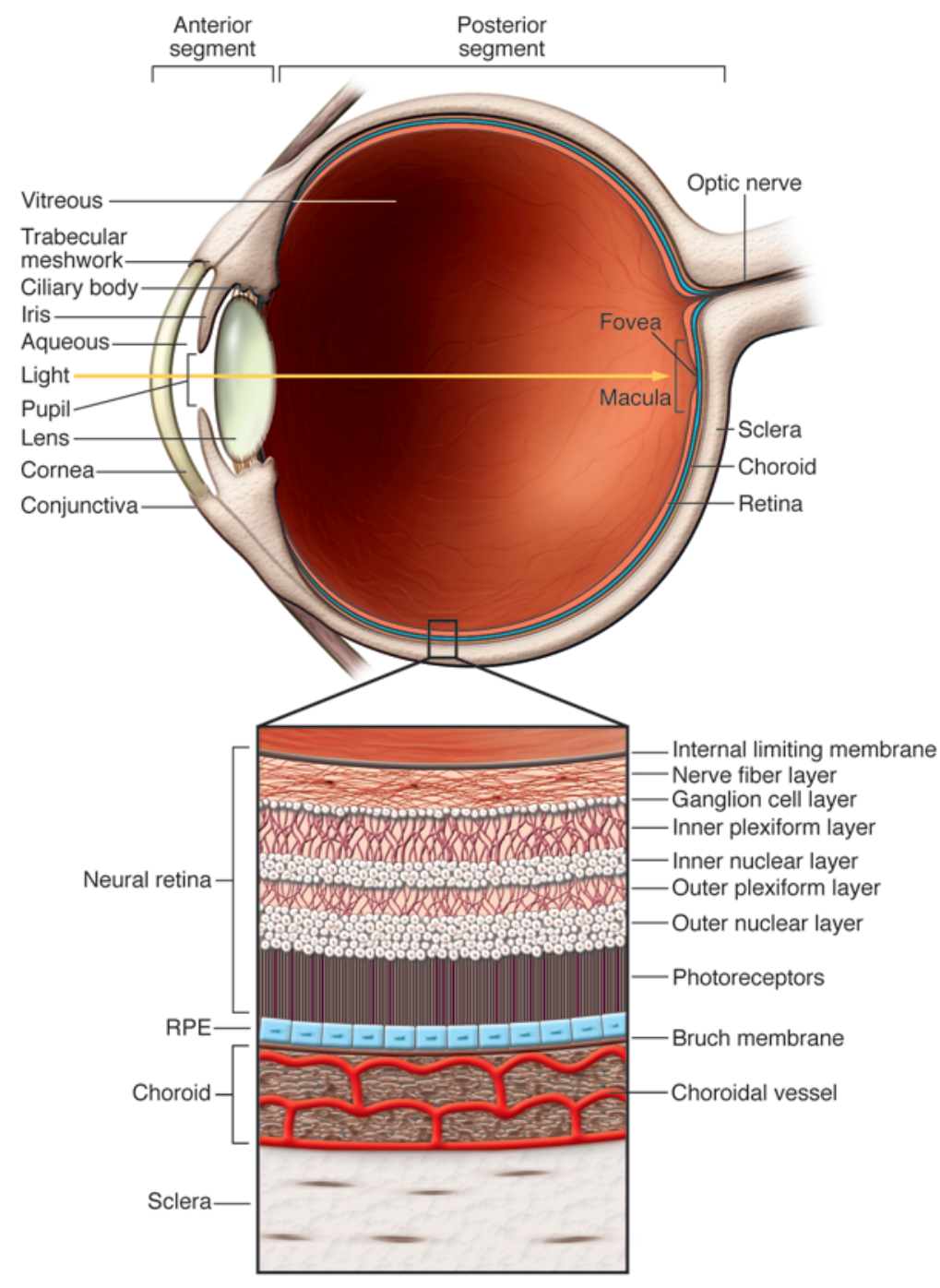

\section{Figure 1}

Scheme of an eye showing major anatomical structures and organization. Detail: Enlarged section of retina and uvea showing anatomical layers. Light passes through the ocular media and concentrates on the macula (the area of the retina responsible for sharp color vision), whereupon the photoreceptor cells sense the signal and transmit it to the brain via the optic nerve. Any damage to the ocular structures along the visual axis would likely result in a visual deficit. RPE, retinal pigment epithelium.

antigen-specific $\mathrm{T}$ cells into the periphery. Indeed, $\mathrm{T}$ cells specific for retinal arrestin can be detected in healthy humans by their proliferation in culture in the presence of retinal arrestin with a frequency of up to 4 per 10 million peripheral blood lymphocytes (17). This is likely to be a gross underestimation of their numbers, as methods that do not rely on proliferation but quantitate the frequency of antigen-reactive T cells directly through the use of MHC-peptide tetramers typically detect 20 -fold-higher retinal antigen-specific $\mathrm{T}$ cell frequencies (18). Additionally, arrestin is only one of at least 10 retinal antigens known to be uveitogenic in animals (8).

$T$ cells reactive to tissue antigens that escape control in the thymus are normally subject to regulation by peripheral tolerance mechanisms, which induce $\mathrm{T}$ cells to become nonresponsive (tolerant) to their specific antigen when they encounter that antigen in healthy tissues, but retinal antigens residing in the eye are relatively inaccessible. Thus, circulating retinal antigen-specific $\mathrm{T}$ cells are likely to be "ignorant" of their cognate antigen rather than tolerant and can be activated by a chance encounter with antigen, possibly in the form of a microbial component that structurally mimics their cognate tissue antigen (19). Indeed, it has been demonstrated that forced expression of a retinal antigen in the periphery (as a transgene, by

extraordinary success of corneal grafts, its role in protection from ocular autoimmunity has been contentious.

It has been convincingly demonstrated that elimination in the thymus of self-reactive T cells, a process known as central tolerance, applies to retinal antigens (11). The mechanisms underlying central tolerance rely on an immature $\mathrm{T}$ cell interacting with its cognate tissue antigen through its specific TCR. Tissue antigens, including the retinal antigens IRBP and arrestin, are ectopically expressed in the thymus under the control of the gene-regulatory protein autoimmune regulator (AIRE) $(12,13)$. Mice made deficient for the Aire gene and humans with AIRE mutations have absent or reduced expression of tissue antigens in the thymus, fail to eliminate autoreactive $\mathrm{T}$ cells, and develop multiorgan autoimmunity (in humans, this condition is known as autoimmune polyendocrinopathy-candidiasis-ectodermal dystrophy [APECED]) (14). Normal thymic expression of IRBP in mice detectably eliminates many $T$ cells expressing TCRs that recognize IRBP, thereby reducing the autoreactive uveitogenic $\mathrm{T}$ cell repertoire (11). However, thymic expression of retinal antigens among individual humans and mouse strains is variable $(15,16)$, and levels of expression insufficiently high to induce the elimination of $\mathrm{T}$ cells bearing cognate TCRs may permit the escape of retinal retroviral delivery, or by vaccination with naked DNA) results in tolerance and in resistance to the subsequent induction of autoimmunity (20-23). Therefore, by sequestering retinal antigens within the eye and hindering peripheral tolerance, immune privilege may actually predispose to ocular autoimmunity (24).

\section{Animal models of uveitis}

Understanding of uveitis has advanced tremendously as a result of the development of animal models of the disease. Experimental autoimmune uveitis (EAU) is induced by immunization of animals with the retinal antigens known to elicit responses in lymphocytes isolated from patients with uveitis. Elicitation of ocular pathology in animals requires coadministration of bacterial adjuvants, such as pertussis toxin and/or CFA, which contains heat-killed tuberculosis bacteria. This triggers bacterial pattern recognition receptors on innate immune cells (monocytes, dendritic cells, neutrophils, NK cells, NKT cells, and $\gamma \delta$ T cells) and provides the proinflammatory immunological milieu required to steer the adaptive immune response toward an autopathogenic effector pathway (see below, innate immune response can by itself result in ocular inflammation in animal models $(25,26)$ and possibly in humans (Table 1$)$. "Basic mechanisms driving uveitis"). In fact, stimulation of the 
Table 1

Some major uveitic conditions and their characteristics ${ }^{A}$

\section{Disease}

Idiopathic uveitis

Sympathetic ophthalmia

Birdshot retinochoroidopathy

Uveitis associated with VKH disease

Anterior uveitis associated with juvenile idiopathic arthritis

Uveitis associated with Behçet disease

Ocular sarcoidosis (associated with systemic sarcoidosis)

Anterior uveitis associated with spondyloarthropathy (HLA-B27 associated)

Anterior uveitis associated with Blau syndrome

\section{Clinical symptoms}

Does not fall under the known classifications below. Can present as anterior, intermediate, posterior, or panuveitis. May lead to blindness, especially if it involves the posterior pole of the eye.

Retinal vasculitis, multifocal choroiditis, intermediate uveitis or panuveitis. Often leads to blindness.

Progressive inflammation of choroid and retina, macular edema, vasculitis, and vitritis. Night blindness and loss of color vision. Fundus takes on a spotted, birdshot-like appearance. May lead to substantial loss of visual acuity.

Granulomatous inflammation of the uvea. Depigmentation of iris and retinal pigment epithelium. Often causes blindness.

Chronic bilateral iridocyclitis, frequent with this particular variety of arthritis. Can lead to vision loss due to secondary complications such as cataract or increased (glaucoma) or decreased (hypotony) intraocular pressure.

Inflammation of the iris, uvea, and retina; vitritis; vasculitis. Poor visual prognosis due to occlusive vasculitis that often leads to blindness.

Granulomatous or nongranulomatous uveitis, anterior and/or posterior with deposits of leukocytes in the form of "mutton fat" keratic precipitates. May lead to blindness if untreated.

Recurrent inflammation of the anterior segment, usually unilateral. May lead to glaucoma and secondary vision loss.

Granulomatous inflammation of the iris. May lead to increased ocular pressure and vision loss if untreated.

\section{Causality}

Unknown. Believed to be autoimmune.

Penetrating wound to one eye and autoimmunization to ocular antigens.

Trigger unknown. Very strong association with HLA A-29 and frequent responses to antigens from the retina suggest autoimmune etiology.

Unknown. Associations with immunological responses to proteins in the melanin synthesis pathway.

Unknown. Autoimmune causes believed likely.

Unknown. Infectious trigger suspected. Associations reported with polymorphisms in NOD2 and IL 15 .

Unknown. Initial microbial trigger suspected. Ocular manifestations of sarcoidosis (unlike systemic) not associated with polymorphisms in NOD2.

Unknown. Microbial trigger suspected (Klebsiella, etc.). Antigenic similarity of B27 molecule and arrestin reported.

Unknown. Infectious trigger suspected. Associations with polymorphisms in NOD2.

AInformation compiled from refs. 1, 3, 100-103; Wikipedia (http://www.wikipedia.org/); and Merck Manuals online (http://www.merck.com/mmpe/sec09/ ch105/ch105a.html).

Because no animal model can reproduce the full complexity of the human disease, it is necessary to develop and use a variety of models to represent the different aspects and diverse clinical/ immunological manifestations of uveitis. The major models of uveitis and their salient points are summarized in Table 2. In general, EAU models can be divided into induced (by immunization) and spontaneous (although the mice have been genetically manipulated). The "classical" EAU model, induced by immunization with retinal antigen in CFA, has without a doubt been the most useful one in terms of dissecting basic cellular and molecular mechanisms of uveitis. By combining the use of specific immunological reagents and genetically manipulated strains of mice, this model has provided most of the insights into the pathogenesis of uveitis (reviewed in refs. 1, 5, 19, 24, 27, 28). This EAU model appears to mimic central features of human disease in terms of clinical appearance (Figure 2) and numerous studies discussed below (see "Determinants of susceptibility: who is predisposed?" and "Basic mechanisms driving uveitis") indicate that it is also a reasonable representation of human uveitis in terms of mechanisms.

Among the other induced EAU models, the "humanized" model of EAU, which is induced in HLA class II transgenic mice, merits particular attention. Arrestin is the ocular antigen to which uveitis patients most frequently respond, but it is not effective at induc- ing uveitis in wild-type mice. However, mice made transgenic for any one of a number of HLA class II alleles, including HLA-DR3 (DRB1*0301), HLA-DR4 (DRB1*0401), HLA-DQ6 (DQB1*0601), and HLA-DQ8 (DQB1*0302) (29), develop EAU after immunization with retinal arrestin (30). In HLA-DR3 transgenic mice, the region of arrestin responsible for pathology was identified to be the same as that recognized by $\mathrm{T}$ cells from patients with uveitis (ref. 31; and M.J. Mattapallil and R.R. Caspi, unpublished observations). Because in mice transgenic for human HLA class II alleles the autoantigen is presented by a human MHC molecule, these animals may help to identify the antigenic regions functionally involved in human disease, which is a prerequisite for defining antigen-specific biomarkers and therapies for human uveitis.

The second category of EAU models comprises those in which disease arises spontaneously. Arguably, in this regard, they are more similar to human disease than the induced EAU models; however, they develop in hosts that have been genetically manipulated and therefore are immunologically very different from normal. Nevertheless, these models can teach us about some of the variables that might bring about susceptibility to disease. Typically, spontaneous uveitis occurs under conditions of enhanced antigenspecific $\mathrm{T}$ cell affinity and/or frequency. One example is mice lacking the transcriptional regulator AIRE, in which deficient thymic 
Table 2

Major animal models of uveitis ${ }^{A}$

\section{Type of model and \\ method of induction}

\section{Monkey models of uveitis}

Immunization with retinal arrestin

emulsified in CFA or Hunter's adjuvant

\section{Rat models of uveitis}

Immunization with retinal antigen in CFA or adoptive transfer of $T$ cells from immunized donors to naive recipients

\section{Induced mouse models of uveitis "Classical" EAU: immunization of WT mice with ocular antigen in CFA or adoptive transfer of immune cells (or cell lines) from immunized donors to naive recipients}

\section{"Humanized" EAU: HLA-DR3 transgenic mice immunized or adoptively transferred as above}

EAU induced by infusion of antigenpulsed syngeneic DCs

EIU

MDP-induced uveitis

Neo-self antigen expressed in the mouse eye transgenically under a retinal promoter or by retroviral transduction following intraocular injection. Mice are then immunized with the specific antigen.

\section{Spontaneous mouse models of uveitis} Deficient central tolerance

Double-transgenic mice expressing a neo-self antigen in the retina and an antigen-specific TCR

Mice transgenic for a human HLA class I antigen associated with uveitis

\section{Examples of models}

Cynomolgus or rhesus monkeys injected in multiple sites at the nape of the neck

Arrestin-induced model in the Lewis rat. Many other retinal and choroidal (melanin) antigens are also uveitogenic in Lewis rats.

EAU induced in B10.RIII, B10.A, and C57BL/6 mice with IRBP

EAU in HLA-DR3 transgenic mice immunized with retinal arrestin or its peptide fragments

B10.RIII mice are given splenic DCs elicited with Flt3L, matured in vitro, and pulsed with IRBP p161-180. The model has not been reported in other mouse strains.

Induced by systemic injection of bacterial LPS in rats and in mice or by local intraocular injection in rabbits

Induced by direct injection of MDP, a NOD2 ligand, into mouse eyes

Transgenic HEL or $\beta$-gal under the control of an eye-specific promoter; or retrovirally introduced influenza HA in the retina.

Spontaneous uveitis in AIRE-deficient mice directed at IRBP; spontaneous uveitis in nude mice implanted with embryonic rat thymus.

Spontaneous EAU-like uveitis in mice expressing ocular HEL and a HEL-specific TCR

HLA-A29 transgenic mice. Birdshot retinochoroidopathy-like disease develops between 8 and 12 months of age
Refs. Comments

104, 105 Used rarely, primarily for preclinical studies. Clinical and histological appearances indistinguishable from human uveitis.

70 Was the major EAU model until the mouse model was reported in 1988. Now used by relatively few groups.

Mycobacteria in CFA provide innate "danger" signals that polarize autoimmune lymphocytes toward a proinflammatory phenotype. PTX is needed as additional adjuvant in less susceptible strains.

30 Same as for classical EAU

83 Requires two injections of DC and PTX. Less severe disease than CFA-EAU and appears mostly dependent on Th1 cells.

25, 26 Rapid onset and short duration. Purely innate-driven; no autoimmune component. Serves as a model for acute anterior uveitis.

35 Mimics uveitis associated with Blau syndrome. Purely innate; no autoimmune component.

43, 106, Uveitogenic T cells needed to be activated 107

13, 32, Higher frequency and higher affinity of 108 cells bearing TCRs specific for IRBP

42-44 Spontaneous nature of disease in these models may at least in part depend on the frequency and affinity of the TCR

33, 34 The actual target antigen is unknown

FIt3L, FMS-like tyrosine kinase 3 ligand; PTX, pertussis toxin. AWith the exception of EIU and MDP-induced uveitis, all models are autoimmune.

expression of tissue antigens such as IRBP and arrestin results in failure to eliminate retina-antigen-specific $T$ cells. These mice develop antibody and $\mathrm{T}$ cell responses directed at IRBP that result in uveitis $(13,32)$. Another example is double-transgenic mice expressing both a foreign protein as a neo-self antigen in the eye and a TCR specific for that protein on most T cells (Table 2). However, data obtained with neoantigen models should be interpreted with some caution, due to uncertainty about whether the location and level of expression of the neoantigen truly mimic those of a native retinal antigen. Furthermore, TCRs specific for neoantigens 
A Human
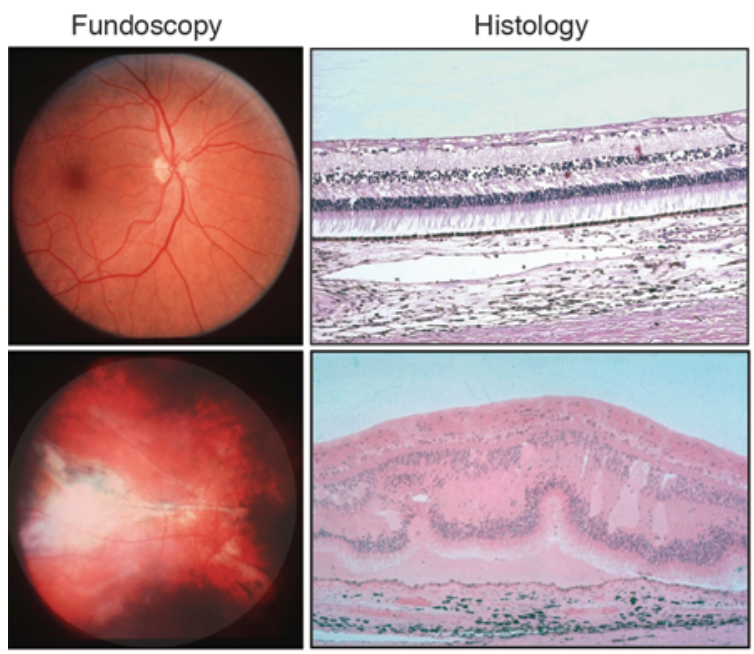

Healthy

Uveitis

\section{B Mouse}

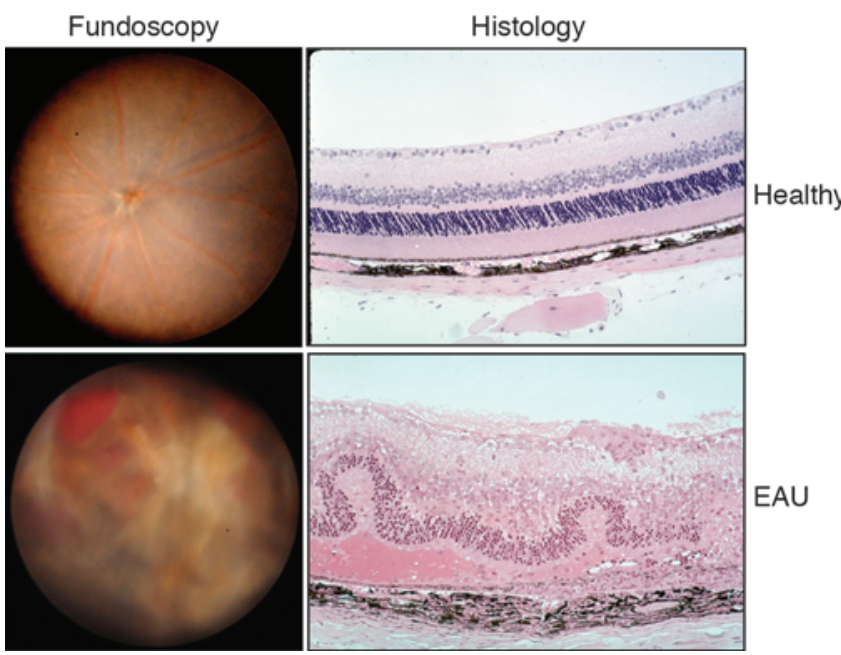

typically have a much higher affinity for their cognate antigen than those specific for native antigen that escape the thymic process of central tolerance; they are thus not representative of typical autoreactive $T$ cells. An intriguing model is spontaneous uveitis that develops between 8 and 12 months of age in HLA-A29 transgenic mice $(33,34)$. HLA-A29 is highly associated with birdshot retinochoroidopathy in humans (Table 1 ). No information is available as to the antigen(s) targeted in HLA-A29 uveitis in humans, and the etiological mechanisms remain obscure. This model may provide a much-needed tool to approach these questions.

The most widely used model of autoinflammatory uveitis driven largely by innate immune mechanisms is endotoxin-induced uveitis (EIU), which can be elicited in rats and in mice by systemic injection of bacterial LPS. The response is acute anterior uveitis of short duration $(25,26)$ (Table 2). While EIU has been useful for dissecting mechanisms of innate inflammation and examining therapeutic modalities, it is not quite clear which human disease the model represents. In that regard, the recently developed uveitis model induced by intraocular injection of muramyl dipeptide (MDP), a ligand of nucleotide-binding oligomerization domain 2

\section{Figure 2}

Clinical and histological appearance of uveitis: human and mouse. (A) Appearance of the fundus (posterior pole of the eye) and retinal histology (original magnification, $\times 200$ ) of a healthy human retina and those from a patient with uveitis. Images provided by Chi-Chao Chan, National Eye Institute, NIH. (B) Fundus $(\times 20)$ and retinal histology $(\times 400)$ of a B10.RIII mouse immunized with IRBP. Lower-right panels of $\mathbf{A}$ and $\mathbf{B}$ reproduced with permission from Immunological Reviews (24).

(NOD2; also known as CARD15), is arguably a better representation of autoinflammatory uveitic diseases such as Blau syndrome, which is associated with mutations in NOD2 (35).

\section{Determinants of susceptibility: who is predisposed?}

Uveitis in humans has thus far been associated primarily with HLA genes. Strong HLA class I and class II associations have been reported for some uveitic diseases (Table 3). Particularly striking are the associations of sympathetic ophthalmia and VKH disease with HLA-DR4 (although VKH is also strongly associated with HLA-DQ4) and of birdshot retinochoroidopathy with HLA-A29 (relative risk of 49-224, depending on the study). Because HLA molecules are involved in antigen presentation, HLA associations are thought to reflect recognition of particular antigen(s) and epitopes. Immune responses in sympathetic ophthalmia as well as VKH disease target melanin-related antigens $(4,36)$. In birdshot retinochoroidopathy, Behçet disease, and intermediate uveitis, immune responses to retinal arrestin have been reported $(5,37)$.

In mice, a "susceptible" H-2 MHC haplotype is a prerequisite for EAU to develop, reminiscent of the strong HLA associations in humans. Examples of EAU-susceptible haplotypes are $\mathrm{H}-2^{\mathrm{b}}$ (which is found in C57BL/10 and C57BL/6 mice), $\mathrm{H}-2^{\mathrm{k}}$ (which is found in B10.BR mice), and $\mathrm{H}-2^{\mathrm{r}}$ (which is found in B10.RIII mice). The hierarchy of susceptibility to EAU after immunization with the retinal protein IRBP is B10.RIII > B10.BR > C57BL (38). Clearly, however, MHC accounts for only a part of the genetic influences predisposing to uveitis. The availability of $\mathrm{H}-2$ congenic mouse strains, which share the same genetic background but have a different $\mathrm{H}-2$ haplotype or share the same $\mathrm{H}-2$ haplotype but differ in genetic background, has allowed researchers to demonstrate that background genes have a major effect on penetrance and severity of disease $(38,39)$. The effects of these genes are complex and involve all aspects of the immune response, including hormonal responses to stress; levels of ectopic tissue antigen expression in the thymus (which translate to efficiency of central tolerance); and innate responses to environmental stimuli acting as adjuvants, which in turn affect the outcome of adaptive immunity. Integration of these diverse genetic effects with those provided by the environment shapes disease pathogenesis.

\section{Basic mechanisms driving uveitis}

Critical checkpoints in the disease process: lessons from animal models. Animal models of uveitis have helped to identify critical checkpoints in the pathogenesis of the disease (Figure 3 ). Activated T cells specific for retinal antigens mediate EAU in animals. These cells can transfer disease from immunized donors to genetically compatible naive recipients and orchestrate the entire process of uveitis. It is believed that $\mathrm{T}$ cells are also central to the pathogenesis of human uveitis. Strong support for this notion comes from the clinical success of approaches that directly target $\mathrm{T}$ cells, includ- 


\section{Table 3}

HLA associations in uveitis

\section{Disease; race (refs.)}

Birdshot retinochoroidopathy; European descent $(37,109,110)$

Behçet disease; European descent, Asian (111-113)

Anterior uveitis in ankylosing spondylitis; European descent (114-116)

VKH disease; Asian $(117,118)$

Sympathetic ophthalmia; various $(119,120)$

Pars planitis associated with MS; European descent (121)

Idiopathic intermediate uveitis (unrelated to MS); European descent (122)

$\begin{array}{cc}\text { HLA genes } & \text { Relative risk } \\ \text { A29 } & 49.9-224.35 \\ \text { B51 } & 4.0-18.2 \\ \text { B27 } & 3.8-20.0^{A} \\ \text { DR8 } & 34.3 \\ \text { DRB1 } 0405 & 46.7-74.5 \\ \text { DQA1 }{ }^{*} 0302 & 12.0 \\ \text { DQB1 }{ }^{*} 0401 & 18.9-41.3 \\ \text { DPB1 } 0501 & 3.8 \\ \text { DRB1 }{ }^{*} 0404 & 5.6 \\ \text { DRB1 } 0405 & 13.7 \\ \text { DQA1 }{ }^{*} 03 & 3.9-12.8 \\ \text { DR2 } & 3.2^{A} \\ \text { DR51 } & 4.8^{A} \\ \text { DR17 } & 14.3^{A} \\ \text { DR3 } & \text { Not reported }\end{array}$

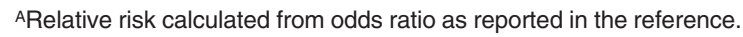

ing macrolide antibiotics such as cyclosporine, FK-506, and mycophenolic acid, which inhibit signaling through the IL-2 receptor pathway that is needed to sustain $\mathrm{T}$ cell activation and function, and antibodies specific for the IL-2 receptor $(40,41)$. The role of antibodies to ocular antigens in disease pathogenesis is less clear. In animals, antibodies in the form of hyperimmune serum are, by themselves, unable to transfer disease to naive recipients, probably because they are too large in molecular size to penetrate the blood-retinal barrier. However, if uveitogenic T cells disrupt the blood-retinal barrier, serum antibodies exacerbate EAU (30). Here, I attempt to systematically present what we have learned about the stages of the disease process using animal models, following the order presented in Figure 3.

As mentioned above, deficiencies in central and peripheral tolerance lead to the presence in healthy individuals of nontolerant retinal antigen-specific $T$ cells that can be activated to acquire effector function. The number of these $T$ cells and the affinity of their TCR for cognate antigen, both of which are determined by the effectiveness of autoreactive $T$ cell elimination in the thymus, can be a predisposing factor to uveitis. T cells from IRBP-deficient mice are more uveitogenic in normal hosts than are $\mathrm{T}$ cells from wild-type mice (11). Additionally, EAU develops spontaneously in mice lacking AIRE, in mice transgenic for an IRBP-specific TCR $(13,32)$, and in double-transgenic mice expressing hen egg lysozyme (HEL) in the eye and a HEL-specific TCR on most T cells (42-44) (Table 2). These findings support the notion that an individual whose $T$ cell repertoire contains retinal antigen-specific $\mathrm{T}$ cells with higher affinity and/or higher frequency (e.g., as a result of reduced expression of retinal antigens in the thymus) $(15,16)$ may have a greater likelihood of developing uveitis.

In addition to cells destined to become effector T cells, the thymus also generates "natural” $\mathrm{T}$ regulatory cells (nTregs). These cells are thought to arise from maturing $\mathrm{T}$ cells whose TCRs have an affinity that is relatively high, but not quite high enough to trigger deletion. They are naturally present in all normal individuals (hence their name) and have been shown to control various manifestations of autoimmunity (45). nTregs also control the threshold of susceptibility to EAU, and their depletion by use of monoclonal antibodies results in greatly enhanced EAU $(11,46)$. nTregs and the effector $T$ cells that they control share the same antigenic specificity, although once activated through their cognate TCR, the nTregs can also act to suppress $T$ cells of other specificities, thus broadening their effectiveness in the context of a response where multiple antigens in the same tissue may be targeted (45). Using IRBP-deficient mice, my laboratory has demonstrated that although generation of nTregs specific to IRBP is dependent on endogenous expression of IRBP, nTregs of other specificities (activated during the process of immunization by as-yet-unidentified signals) may also participate in controlling EAU (46). Furthermore, despite extensive evidence that peripheral tolerance to sequestered retinal antigens is minimal, it may not be entirely absent. Recently, double-transgenic mice expressing $\beta$-gal as a neoretinal antigen and $\beta$-gal-specific TCRs have been shown to exhibit some reduction in responses to $\beta$-gal despite apparent absence of its ectopic expression in the thymus. This suggests that some low level of preexisting peripheral tolerance to antigens within the eye may exist (47). Nevertheless, it remains to be confirmed whether this also applies to native retinal antigens.

In individuals who develop uveitis in any one of its various manifestations (Table 1), the threshold of susceptibility set by nTregs has evidently been passed. The triggers responsible for activating retinal antigen-specific cells so that they escape from nTreg control are largely unknown in humans. One possible exception is sympathetic ophthalmia. This disease is precipitated by ocular trauma to one eye, followed by destructive inflammation in the nontraumatized, or "sympathizing," eye. It is thought that antigens released from the traumatized eye find their way into the draining lymph node and elicit systemic immunity. An accompanying infection may provide an adjuvant effect (although severe endophthalmitis, which quickly destroys the injured eye and eliminates the source of antigen, may actually lessen chances of developing the disease) (3). In uveitic disease that cannot be linked to a trauma, it is believed that $\mathrm{T}$ cells capable of recognizing retinal antigens are primed in the periphery by microbial stimuli that 


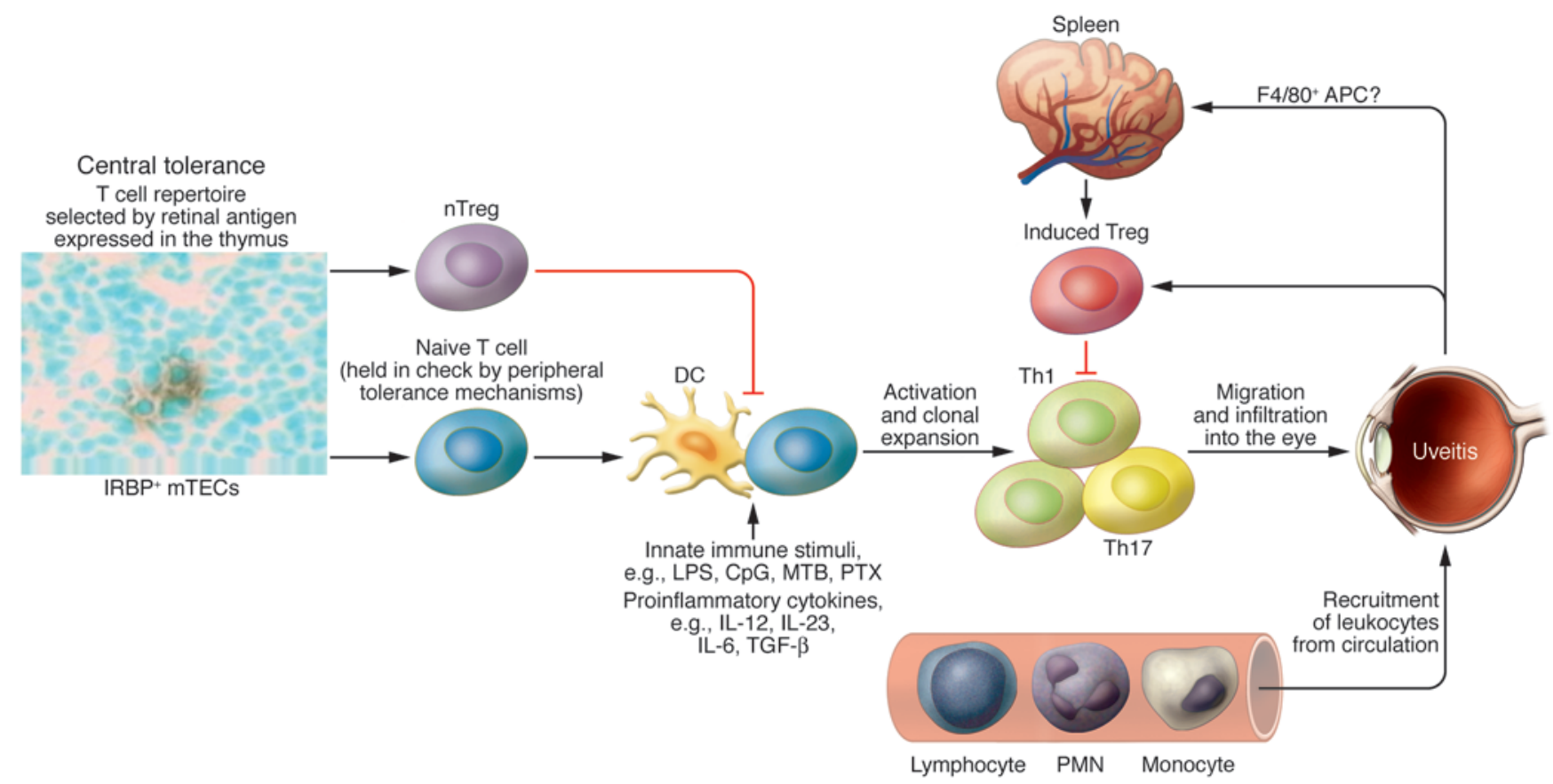

Figure 3

Critical checkpoints in uveitis, as defined from studies with animal models. Retinal antigen-specific T cells that have not been eliminated in the thymus encounter an activating stimulus in the context of costimulatory "danger" signals, escape from the control of nTregs, and differentiate into pathogenic effector T cells. These undergo clonal expansion, migrate to the eye, break down the blood-retinal barrier, and recruit inflammatory leukocytes from the circulation. The resulting inflammation results in damage to the tissue and release of ocular antigens, which triggers eye-specific regulatory mechanisms that terminate the disease and limit pathology. mTECs, medullary thymic epithelial cells. Modified with permission from Immunological Reviews (24).

may be immunologically similar in structure to their cognate retinal antigen (antigenic mimicry) (48-50). Microbial components also interact with innate pattern recognition receptors on APCs, generating "danger" signals that are necessary to elicit inflammatory immune reactions. Animal models of uveitis based on immunization of laboratory animals with retinal antigens in CFA, which contains heat-killed mycobacteria, seek to duplicate this principle by introducing the uveitogenic antigen in the context of microbial "danger" signals.

Following exposure to a uveitogenic stimulus, circulating retinal antigen-specific cells become activated and acquire effector function. Experiments with adoptive transfer of retinal antigen-specific effector $\mathrm{T}$ cells versus nonspecific $\mathrm{T}$ cells, activated ex vivo and fluorescently labeled, have led to the conclusion that a very small number of infused cells infiltrate the eye within hours after transfer, reaching the eye entirely by chance $(51,52)$. They recognize their specific antigen there and cause changes within the eye that bring about development of disease several days later. The APCs within the retina have still not been positively identified. Although there are resident dendritic cells in the retina that could serve as APCs, their expression of MHC class II molecules is low, at least until inflammation is underway (53). CD45 cells derived from the circulation are sufficient to provide APC function, even without eye-resident APCs (54). It can be calculated by infusing labeled retina-antigen-specific $\mathrm{T}$ cells that fewer than ten such $\mathrm{T}$ cells must reach the eye to trigger the early changes leading to EAU (24). In the meantime, the bulk of the transferred cells take up residence in the spleen, where they proliferate and undergo a maturation process that includes upregulation of the chemokine receptor CXCR3 (55). On day four, the retinal antigen-specific $\mathrm{T}$ cells leave the spleen and migrate to the eye, where they reactivate and drive the inflammatory process started by the initial infiltrating cells, by secreting cytokines and chemokines, activating the retinal vasculature, and promoting massive recruitment of inflammatory leukocytes from the circulation. It is these recruited leukocytes, which include neutrophils, monocytes, and "nonspecific" polyclonal T cells, that serve as the final mediators of tissue damage (Figure 3). Each of the recruited cell types apparently provides an essential function, as depletion of any one of them reduces the severity of $\operatorname{EAU}(53,56,57)$.

It should be emphasized that innate immune cells such as $\gamma \delta$ $\mathrm{T}$ cells, NKT cells, and monocytes/macrophages are important not only as final effectors of inflammatory tissue damage, but also as active participants in shaping the effector $\mathrm{T}$ cell response that leads to uveitis. Thus, NK and NKT cells may produce innate IFN- $\gamma$ that is protective in EAU $(58,59)$. Monocytic cells, in addition to functioning as inflammatory cells, can also differentiate to a regulatory phenotype, known as myeloid-derived suppressor cells, which inhibit autoaggressive T cells (60). Conversely, $\gamma \delta$ $T$ cells appear to promote differentiation of autopathogenic effector T cells in EAU by producing cytokines and possibly by acting as APCs (61). The nature of these autopathogenic effector T cells has recently been the subject of much interest and debate and merits its own section. It is discussed in more detail in the section below dealing with pathogenic effector T cells (Pathogenic effector T cells: who is directing the action?). 
While natural regulatory mechanisms set the threshold of susceptibility to disease (46), its termination likely depends on induced regulatory mechanisms. It is well established that T cells exposed to their cognate antigen in the presence of the appropriate environmental cues, such as TGF- $\beta$, can acquire a regulatory function that permits them to suppress the effector function of other $\mathrm{T}$ cells (62). The eye, as part of its immune-privileged status, is able to promote in vivo induction of systemic regulatory responses such as anterior chamber-associated immune deviation (ACAID) and post-recovery tolerance (reviewed in ref. 63). ACAID is a complex regulatory phenomenon whereby an antigen injected into the anterior chamber of the eye is transported via the blood into the spleen by eye-derived APCs. There, it induces the generation of antigen-specific $\mathrm{CD}^{+}$and $\mathrm{CD}^{+}$regulatory $T$ cells through a complex mechanism involving B cells and NKT cells (64). These $\mathrm{CD}^{+}$and $\mathrm{CD}^{+}$regulatory $\mathrm{T}$ cells inhibit the acquisition and expression, respectively, of effector function by antigen-specific $T$ cells. Although its relevance to autoimmunity has been contested (partly due to the fact that most studies used ovalbumin as antigen and delayed-type hypersensitivity as the only readout), ACAID or ACAID-like mechanisms might limit immune reactions to retinal antigens following ocular trauma. In addition, in animals that recovered from EAU, post-recovery $\mathrm{CD}^{+}$regulatory $\mathrm{T}$ cells have been described, and these cells appear to be distinct from ACAID-induced regulatory cells (65). Their induction is dependent on the presence of the eye (they are not induced in enucleated animals immunized as for EAU) and on expression of melanocortin-5 receptor by $\mathrm{T}$ cells (66). It has been proposed that the dependence on the eye reflects involvement of $\alpha$-melanocyte-stimulating hormone ( $\alpha$-MSH) present in ocular fluids, but direct evidence to support this is lacking. Importantly, some types of syndromes that include uveitis (such as Behçet and VKH) are reported to be associated with reduced regulatory $\mathrm{T}$ cell number and/or function, although the origin of the affected regulatory T cells (natural, induced, or both) is not clear $(67,68)$.

T cells with regulatory phenotype are found in the eyes of rats and mice with EAU and may act locally to control inflammation (69). Although regulatory $\mathrm{T}$ cells may enter the eye from the circulation, in vitro data suggest that the ocular microenvironment could be conducive to local induction of regulatory $\mathrm{T}$ cells. Ocular fluids contain high levels of TGF- $\beta 2$ and appear to promote regulatory $\mathrm{T}$ cell induction in culture in a TGF- $\beta$-dependent manner (63). Furthermore, ocular pigmented epithelia cocultured with "conventional" $\mathrm{T}$ cells has been reported to promote conversion of those $\mathrm{T}$ cells to regulatory $\mathrm{T}$ cells (63). It remains to be demonstrated, however, that such a conversion occurs in vivo, within the living eye.

Pathogenic effector T cells: who is directing the action? Considerable attention has been directed toward determining the lineage and cytokine profile of uveitogenic effector $T$ cells. This issue has direct clinical significance, as it identifies the $\mathrm{T}$ cell subset(s) and/or lineage(s) that might be a therapeutic target. $\mathrm{CD} 4^{+}$but not $\mathrm{CD}^{+}$ $\mathrm{T}$ cells are necessary for EAU development. Depletion of $\mathrm{CD}^{+}$ $\mathrm{T}$ cells prevents EAU, and highly purified $\mathrm{CD} 4^{+} \mathrm{T}$ cells and $\mathrm{T}$ cell lines specific for retinal antigens transfer EAU into naive recipients (70). Although retinal antigen-specific $\mathrm{CD}^{+} \mathrm{T}$ cells cultured in the laboratory can induce retinal pathology in rodents (71-73), they are not necessary to elicit EAU. Mice and rats depleted of $\mathrm{CD}^{+}$ T cells develop full-blown EAU upon immunization with a uveitisinducing antigen (74). Furthermore, antigen-specific $\mathrm{CD}^{+} \mathrm{T}$ cells can also act as regulatory cells to control EAU (75-77).
A body of evidence has accumulated over the years implicating $\mathrm{CD}^{+}$Th1 effector cells, which predominantly produce the cytokine IFN- $\gamma$, in experimental and clinical uveitis $(3,27,78)$. However, it has recently become clear that $\mathrm{CD}^{+}$effector cells that predominantly produce the cytokine IL-17 (so called Th17 cells) may have an important role in ocular pathology $(79,80)$. Indeed, neutralization of IL-17 in mice prevents and reverses EAU, in contrast to neutralization of IFN $-\gamma$, which exacerbates it $(80,81)$. This is a still unresolved paradox, which has been seen also in experimental arthritis and experimental allergic encephalomyelitis, and has lent apparent credence to the notion that IL-17-producing Th17 cells, and not IFN- $\gamma$-producing Th1 cells, are the true mediators of tissue-specific autoimmunity (78). However, accumulating evidence indicates that Th1 and Th17 cells can both have a pathogenic role (reviewed in ref. 82). In EAU, one or the other lineage can predominate as a pathogenic effector, depending on the model studied. Thus, while EAU induced by injection of IRBP and CFA is IL-17 dependent, and is prevented using neutralizing IL-17-specific antibodies, EAU induced with antigen-pulsed mature dendritic cells seems to require IFN- $\gamma$-producing effector $\mathrm{T}$ cells, as Ifng-knockout mice fail to develop EAU when injected with uveitogenic dendritic cells that induce EAU in wild-type mice $(80,83)$. Notably, polarized Th1 and polarized Th17 cells are both able to transfer EAU into naive recipients, independent of the ability of the recipient to produce the reciprocal effector cytokine, suggesting that Th1 and Th17 each represent a fully competent uveitogenic effector phenotype. It thus appears that either a Th17 or a Th1 effector response can drive ocular autoimmunity.

Extrapolating from the models of EAU induced by IRBP in CFA versus antigen-pulsed dendritic cells, the dominant effector Th phenotype appears to be largely determined by the milieu present during initial recognition of the autoantigen by the immune system. Presentation of antigen in the context of mycobacteria (which are present in CFA) by the diverse APC population present in the lymph node appears to promote a dominant Th17 response, whereas antigen presented by dendritic cells matured in vitro promotes a Th1 response. The initial eliciting event(s) connected to human uveitis is largely unknown, but if the two EAU models discussed above are applicable to humans, the events surrounding initial antigen exposure may be critical to the nature of the subsequent disease.

An important lesson to be learned from these findings is that different autoimmune response profiles can be associated with destructive pathology in the eye. Human uveitis is clinically heterogeneous, even though patients may respond to the same retinal antigen(s). Ocular inflammation in humans has been associated in some cases with a Th1-like cytokine profile, and more recently the presence of Th17 responses has been reported (79, 84-87). However, it is still unclear whether such responses in these patients are causally related to uveitis and represent a valid therapeutic target, especially in the case of patients whose uveitis is part of a systemic syndrome, as they could simply be a consequence of an overactive systemic immune response. Ongoing clinical trials targeting IL-17 in uveitis (http://clinicaltrials.gov/ct2/show/NCT00685399) may soon provide answers to these questions.

\section{Therapeutic implications}

Ideally, an experimental therapy should be able to prevent disease and reverse a disease process that has already set in. However, therapies that only prevent disease may be of value, since chronic autoimmunity involves constant priming of new lymphocytes. 
This process may include immune recognition over time of new antigenic specificities as a result of ongoing exposure to autoantigens released from damaged tissue (88). Historically, therapeutic approaches used successfully to modulate disease in EAU models have often shown efficacy in the clinic; for example, T cell-targeting therapies such as cyclosporine, FK-506, and rapamycin, which are already FDA approved and in clinical use $(3,27,89)$. Anti-TNF therapy, which was effective in experimental uveitis (90), has been efficacious in controlling uveitis associated with seronegative spondyloarthropathies and juvenile idiopathic arthritis (91). IFN- $\alpha$ is being used with considerable success to treat uveitis in patients with Behçet disease and has been approved in Europe (although not yet in the United States) for this indication (92). Two other therapeutic approaches that are showing promising results in clinical trials are oral tolerance, which should be explored further, and IL-2 receptor-directed therapy using the humanized CD25-specific antibody daclizumab (27).

Next-generation approaches to therapy might take advantage of tolerogenic administration of retinal antigen to correct defects in peripheral tolerance and to enhance regulatory $\mathrm{T}$ cell numbers and/or function. The utility of antigen-specific therapy in humans is suggested by encouraging results in a clinical trial mentioned above using oral tolerance to arrestin (27). Peripheral de novo tolerogenic expression of retinal antigens can be achieved in the adult by naked DNA vaccination with an IRBP expression plasmid or by infusion of autologous B cells engineered by retroviral transduction to express a uveitogenic fragment of $\operatorname{IRBP}(22,23)$. Importantly, this tolerogenic B cell-based therapy has been shown to control EAU in HLA-DR3 transgenic mice (93) and could have significant clinical potential.

The pathogenic effector cytokines produced by uveitogenic $\mathrm{T}$ cells and recruited inflammatory leukocytes may serve as targets for inhibition or neutralization. As mentioned above, TNF- $\alpha$ neutralization is already in clinical use (91). The finding that neutralization of IL-17 by monoclonal antibodies in mice aborts EAU, even when instituted after the uveitogenic effector $\mathrm{T}$ cells have already been generated (80), suggests potential clinical efficacy. As mentioned above, clinical trials examining IL-17 neutralization therapy in uveitis are ongoing.

Inhibition of migration and recruitment of inflammatory cells into the eye could be achieved by targeting adhesion molecules and/or chemokines and chemokine receptors. Blockade of the integrin very late activation antigen-4 (VLA4) ameliorates EAU in mice (94). As VLA4-specific monoclonal antibody is an FDAapproved treatment for multiple sclerosis and Crohn disease
(95), it is conceivable that the approach could be considered as a therapy for uveitis. Similarly, blocking the integrin lymphocyte function-associated antigen 1 (LFA-1) or its ligand intercellular adhesion molecule 1 (ICAM-1) inhibits EAU, as does blockade of CD44 (the receptor for hyaluronan, osteopontin, collagens, and matrix metalloproteinases) $(94,96,97)$. Amelioration of EAU has also been achieved by blockade of the chemokine receptors CXCR3 and CXCR5, which are important for migration of uveitogenic and recruited cells into the eye $(55,98)$.

\section{Future directions}

Knowledge of the critical checkpoints in the pathogenesis of uveitis (Figure 3 ) is providing the clinician with relevant targets for immunotherapeutic intervention. Therapies have been moving away from general immunosuppression toward the use of increasingly specific biologicals, targeting defined aspects of the immune response. Nevertheless, therapies directed at components shared by activated immune cells, such as adhesion molecules or cytokines/chemokines and their receptors, may have the unwanted consequence of inhibiting antimicrobial defense and antitumor surveillance mechanisms (99). Furthermore, they are only symptomatic and do not treat the underlying cause of the breakdown of self tolerance. The "holy grail" for clinicians treating patients with uveitis is a therapy that will uniquely target the retinal antigenspecific $T$ cells that drive the disease. Our knowledge of the retinal proteins that may drive uveitis in humans is increasing; however, to devise effective antigen-specific approaches to diagnosis and treatment, we need to know more about their HLA dependence and epitope specificity, and whether antigen recognition may change during the course of disease. "Humanized" models of uveitis in HLA transgenic mice may be of help in these studies. The examples discussed in this Review underscore the contribution of basic research in animal models to unraveling the mechanisms driving ocular autoimmune and autoinflammatory disease and highlight their importance in the continued development of novel therapies to combat these sight-threatening conditions.

\section{Acknowledgments}

I am grateful to Chi-Chao Chan for providing EAU scoring criteria as well as histology pictures of EAU and human uveitis.

Address correspondence to: Rachel R. Caspi, Laboratory of Immunology, National Eye Institute, NIH, Bethesda, Maryland 20892, USA. Phone: 301.435.4555; Fax: 301.480.6668; E-mail: rcaspi@helix.nih.gov.
1. Gery I, Nussenblatt RB, Chan CC, Caspi RR. Autoimmune diseases of the eye. In: Theofilopoulos AN, Bona CA, eds. The Molecular Pathology of Autoimmune Diseases. New York, New York, USA: Taylor and Francis; 2002:978-998.

2. Gritz DC, Wong IG. Incidence and prevalence of uveitis in Northern California; the Northern California Epidemiology of Uveitis Study. Ophthalmology. 2004;111(3):491-500.

3. Nussenblatt RB, Whitcup SM. Uveitis: Fundamentals and Clinical Practice. Philadelphia, Pennsylvania, USA: Mosby Publishing; 2004.

4. Gocho K, Kondo I, Yamaki K. Identification of autoreactive $\mathrm{T}$ cells in Vogt-Koyanagi-Harada disease. Invest Ophthalmol Vis Sci. 2001;42(9):2004-2009.

5. Gery I, Mochizuki M, Nussenblatt RB. Retinal specific antigens and immunopathogenic processes they provoke. Prog Retinal Res. 1986;5:75-109.
6. Pennesi G, Caspi RR. Genetic control of susceptibility in clinical and experimental uveitis. Int Rev Immunol. 2002;21(2-3):67-88.

7. Caspi RR. Mouse models of autoimmune and immune-mediated uveitis. In: Chalupa L, ed. Eye, Retina, and Visual System of the Mouse. Cambridge, Massachusetts, USA: MIT Press; 2008: 513-526.

8. Caspi RR. Animal models of autoimmune and immune-mediated uveitis. Drug Discov Today: Disease Models. 2006;3(1):3-10.

9. Streilein JW. Ocular immune privilege: the eye takes a dim but practical view of immunity and inflammation. J Leukoc Biol. 2003;74(2):179-185.

10. Medawar P. Immunity to homologous grafted skin III. The fate of skin homografts transplanted to the brain, to subcutaneous tissue, and to the anterior chamber of the eye. BrJ Exp Pathol. 1948;29(1):58-69.

11. Avichezer D, et al. An immunologically privileged retinal antigen elicits tolerance: major role for central selection mechanisms. J Exp Med. 2003; 198(11):1665-1676.

12. Gotter J, Brors B, Hergenhahn M, Kyewski B. Medullary epithelial cells of the human thymus express a highly diverse selection of tissue-specific genes colocalized in chromosomal clusters. J Exp Med. 2004;199(2):155-166.

13. Anderson MS, et al. Projection of an immunological self shadow within the thymus by the aire protein. Science. 2002;298(5597):1395-1401.

14. Mathis D, Benoist C. Aire. Annu Rev Immunol. 2009; 27:287-312.

15. Egwuagu CE, Charukamnoetkanok P, Gery I. Thymic expression of autoantigens correlates with resistance to autoimmune disease. J Immunol. 1997; 159(7):3109-3112.

16. Takase $\mathrm{H}$, et al. Thymic expression of peripheral tissue 
antigens in humans: a remarkable variability among individuals. Int Immunol. 2005;17(8):1131-1140.

17. de Smet MD, Dayan M, Nussenblatt RB. A novel method for the determination of T-cell proliferative responses in patients with uveitis. Ocul Immunol Inflamm. 1998;6(3):173-178.

18. Tan LC, et al. A re-evaluation of the frequency of CD8+ T cells specific for EBV in healthy virus carriers. J Immunol. 1999;162(3):1827-1835.

19. Wildner G, Diedrichs-Mohring M. Autoimmune uveitis and antigenic mimicry of environmental antigens. Autoimmun Rev. 2004;3(5):383-387.

20. McPherson SW, Roberts JP, Gregerson DS. Systemic expression of rat soluble retinal antigen induces resistance to experimental autoimmune uveoretinitis. J Immunol. 1999;163(8):4269-4276

21. Xu H, et al. Transgenic expression of an immunologically privileged retinal antigen extraocularly enhances self tolerance and abrogates susceptibility to autoimmune uveitis. Eur Immunol. 2000;30(1):272-278.

22. Agarwal RK, Kang Y, Zambidis E, Scott DW, Chan CC, Caspi RR. Retroviral gene therapy with an immunoglobulin-antigen fusion construct protects from experimental autoimmune uveitis. JClin Invest. 2000;106(2):245-252.

23. Silver PB, et al. Hydrodynamic vaccination with DNA encoding an immunologically privileged retinal antigen protects from autoimmunity through induction of regulatory T cells. J Immunol. 2007; 179(8):5146-5158

24. Caspi RR. Ocular autoimmunity: the price of privilege? Immunol Rev. 2006;213:23-35.

25. Rosenbaum JT, McDevitt HO, Guss RB, Egbert PR Endotoxin-induced uveitis in rats as a model for human disease. Nature. 1980;286(5773):611-613.

26. Li Q, Peng B, Whitcup SM, Jang SU, Chan CC. Endotoxin induced uveitis in the mouse: susceptibility and genetic control. Exp Eye Res. 1995; 61(5):629-632

27. Nussenblatt RB. Bench to bedside: new approaches to the immunotherapy of uveitic disease. Int Rev Immunol. 2002;21(2-3):273-289.

28. Gregerson DS. Peripheral expression of ocular antigens in regulation and therapy of ocular autoimmunity. Int Rev Immunol. 2002;21(2-3):101-121.

29. Taneja V, David CS. HLA class II transgenic mice as models of human diseases. Immunol Rev. 1999; 169:67-79.

30. Pennesi G, et al. A humanized model of experimental autoimmune uveitis in HLA class II transgenic mice. J Clin Invest. 2003;111(8):1171-1180.

31. de Smet MD, Bitar G, Roberge FG, Gery I, Nussenblatt RB. Human S-antigen: presence of multiple immunogenic and immunopathogenic sites in the Lewis rat. J Autoimmun. 1993;6(5):587-599.

32. DeVoss J, et al. Spontaneous autoimmunity prevented by thymic expression of a single self-antigen. J Exp Med. 2006;203(12):2727-2735

33. Szpak Y, et al. Spontaneous retinopathy in HLAA29 transgenic mice. Proc Natl Acad Sci U S A. 2001;98(5):2572-2576

34. de Kozak Y, Camelo S, Pla M. Pathological aspects of spontaneous uveitis and retinopathy in HLAA29 transgenic mice and in animal models of retinal autoimmunity: relevance to human pathologies. Ophthalmic Res. 2008;40(3-4):175-180.

35. Rosenzweig HL, et al. NOD2, the gene responsible for familial granulomatous uveitis, in a mouse model of uveitis. Invest Ophthalmol Vis Sci. 2008; 49(4):1518-1524

36. Lin X, Li S, Xie C, Huang X, Fan Z. Experimental studies of melanin associated antigen and its relationship with sympathetic ophthalmia and Vogt-Kayanagi-Harada syndrome. Yan Ke Xue Bao. 2003;19(3):184-186, 200.

37. Nussenblatt RB, Mittal KK, Ryan S, Green WR, Maumenee AE. Birdshot retinochoroidopathy associated with HLA-A29 antigen and immune responsiveness to retinal S-antigen. Am J Ophthalmol. 1982;94(2):147-158.

38. Caspi RR, Grubbs BG, Chan CC, Chader GJ, Wiggert B. Genetic control of susceptibility to experimental autoimmune uveoretinitis in the mouse model. Concomitant regulation by $\mathrm{MHC}$ and nonMHC genes. J Immunol. 1992;148(8):2384-2389.

39. Mattapallil MJ, et al. Differentially expressed genes in MHC-compatible rat strains that are susceptible or resistant to experimental autoimmune uveitis. Invest Ophthalmol Vis Sci. 2008;49(5):1957-1970.

40. Kulkarni P. Review: uveitis and immunosuppressive drugs. J Ocul Pharmacol Ther. 2001;17(2):181-187.

41. Nussenblatt RB, et al. Treatment of noninfectious intermediate and posterior uveitis with the humanized anti-Tac mAb: a phase I/II clinical trial. Proc Natl Acad Sci U S A. 1999;96(13):7462-7466

42. Zhang $M$, et al. $T$ cell tolerance to a neo-self antigen expressed by thymic epithelial cells: the soluble form is more effective than the membrane-bound form. J Immunol. 2003;170(8):3954-3962.

43. Ham DI, et al. Central immunotolerance in transgenic mice expressing a foreign antigen under control of the rhodopsin promoter. Invest Ophthalmol Vis Sci. 2004;45(3):857-862

44. Lambe $T$, et al. Limited peripheral $\mathrm{T}$ cell anergy predisposes to retinal autoimmunity. J Immunol. 2007;178(7):4276-4283

45. Sakaguchi S, Sakaguchi N. Regulatory T cells in immunologic self-tolerance and autoimmune disease. Int Rev Immunol. 2005;24(3-4):211-226.

46. Grajewski RS, et al. Endogenous IRBP can be dispensable for generation of natural CD4+CD25+ regulatory $\mathrm{T}$ cells that protect from IRBP-induced retinal autoimmunity. J Exp Med. 2006;203(4):851-856.

47. Gregerson DS, Heuss ND, Lehmann U, McPherson SW. Peripheral induction of tolerance by retinal antigen expression. J Immunol. 2009;183(2):814-822.

48. Wildner G, Diedrichs-Moehring M. Multiple autoantigen mimotopes of infectious agents induce autoimmune arthritis and uveitis in lewis rats. Clin Diagn Lab Immunol. 2005;12(5):677-679.

49. Singh VK, Usukura J, Shinohara T. Molecular mimicry: uveitis induced in Macaca fascicularis by microbial protein having sequence homology with retinal S-antigen. Jpn J Ophthalmol. 1992;36(1):108-116.

50. Shinohara T, Singh VK, Tsuda M, Yamaki K, Abe $\mathrm{T}$, Suzuki S. S-antigen: from gene to autoimmune uveitis. Exp Eye Res. 1990;50(6):751-757.

51. Prendergast RA, et al. T cell traffic and the inflammatory response in experimental autoimmune uveoretinitis. Invest Ophthalmol Vis Sci. 1998; 39(5):754-762.

52. Thurau SR, et al. The fate of autoreactive, GFP+ $\mathrm{T}$ cells in rat models of uveitis analyzed by intravital fluorescence microscopy and FACS. Int Immunol. 2004;16(11):1573-1582.

53. Jiang HR, Lumsden L, Forrester JV. Macrophages and dendritic cells in IRBP-induced experimental autoimmune uveoretinitis in B10RIII mice. Invest Ophthalmol Vis Sci. 1999;40(13):3177-3185.

54. Gregerson DS, Sam TN, McPherson SW. The antigen-presenting activity of fresh, adult parenchymal microglia and perivascular cells from retina. J Immunol. 2004;172(11):6587-6597.

55. Chen J, et al. A unique pattern of up- and down-regulation of chemokine receptor CXCR3 on inflammation-inducing Th1 cells. Eur J Immunol. 2004; 34(10):2885-2894

56. Caspi RR, et al. Recruitment of antigen-nonspecific cells plays a pivotal role in the pathogenesis of a $\mathrm{T}$ cell-mediated organ-specific autoimmune disease, experimental autoimmune uveoretinitis. J Neuroimmunol. 1993;47(2):177-188.

57. Su SB, et al. Altered chemokine profile associated with exacerbated autoimmune pathology under conditions of genetic interferon-gamma deficiency. Invest Ophthalmol Vis Sci. 2007;48(10):4616-4625.
58. Tarrant TK, Silver PB, Chan CC, Wiggert B, Caspi RR. Endogenous IL-12 is required for induction and expression of experimental autoimmune uveitis. J Immunol. 1998;161(1):122-127.

59. Grajewski RS, et al. Activation of invariant NKT cells ameliorates experimental ocular autoimmunity by a mechanism involving innate IFN-gamma production and dampening of the adaptive Th1 and Th17 responses. JImmunol. 2008;181(7):4791-4797.

60. Nicholson LB, Raveney BJ, Munder M. Monocyte dependent regulation of autoimmune inflammation. Curr Mol Med. 2009;9(1):23-29.

61. Cui Y, et al. Major role of gamma delta T cells in the generation of IL-17+ uveitogenic T cells. J Immunol. 2009;183(1):560-567.

62. Horwitz DA, Zheng SG, Gray JD. Natural and TGFbeta-induced Foxp3(+)CD4(+) CD25(+) regulatory $\mathrm{T}$ cells are not mirror images of each other. Trends Immunol. 2008;29(9):429-435.

63. Stein-Streilein J, Taylor AW. An eye's view of T regulatory cells. J Leukoc Biol. 2007;81(3):593-598.

64. Stein-Streilein J, Streilein JW. Anterior chamber associated immune deviation (ACAID): regulation, biological relevance, and implications for therapy. Int Rev Immunol. 2002;21(2-3):123-152.

65. Kitaichi N, Namba K, Taylor AW. Inducible immune regulation following autoimmune disease in the immune-privileged eye. J Lenkoc Biol. 2005; 77(4):496-502.

66. Taylor A. A review of the influence of aqueous humor on immunity. Ocul Immunol Inflamm. 2003; 11(4):231-241

67. Chen L, et al. Decreased frequency and diminished function of $\mathrm{CD} 4+\mathrm{CD} 25$ high regulatory $\mathrm{T}$ cells are associated with active uveitis in patients with VogtKoyanagi-Harada syndrome. Invest Ophthalmol Vis Sci. 2008;49(8):3475-3482.

68. Nanke Y, Kotake S, Goto M, Ujihara H, Matsubara M, Kamatani N. Decreased percentages of regulatory $\mathrm{T}$ cells in peripheral blood of patients with Behcet's disease before ocular attack: a possible predictive marker of ocular attack. Mod Rheumatol. 2008;18(4):354-358.

69. Ke Y, Jiang G, Sun D, Kaplan HJ, Shao H. Ocular regulatory $\mathrm{T}$ cells distinguish monophasic from recurrent autoimmune uveitis. Invest Ophthalmol Vis Sci. 2008;49(9):3999-4007.

70. Agarwal RK, Caspi RR. Rodent models of experimental autoimmune uveitis. Methods Mol Med. 2004; 102:395-419.

71. McPherson SW, Yang J, Chan CC, Dou C, Gregerson DS. Resting CD8 T cells recognize beta-galactosidase expressed in the immune-privileged retina and mediate autoimmune disease when activated. Immunology. 2003;110(3):386-396

72. Song L, Le J, Ye F, Shao H, Kaplan HJ, Sun D. Sequence 168 to 177 of interphotoreceptor retinoid-binding protein (IRBP) is an antigenic epitope for autoreactive CD8 T cells in the B10RIII mouse. J Neuroimmunol. 2008;193(1-2):68-76.

73. Shao H, Sun SL, Kaplan HJ, Sun D. Characterization of rat CD8+ uveitogenic $\mathrm{T}$ cells specific for interphotoreceptor retinal-binding protein 1177 1191. J Immunol. 2004;173(4):2849-2854.

74. Calder VL, Zhao ZS, Wang Y, Barton K, Lightman SL. Effects of CD8 depletion on retinal soluble antigen induced experimental autoimmune uveoretinitis. Immunology. 1993;79(2):255-262.

75. Caspi RR, Kuwabara T, Nussenblatt RB. Characterization of a suppressor cell line which downgrades experimental autoimmune uveoretinitis in the rat. J Immunol. 1988;140(8):2579-2584.

76. Han G, et al. Suppressor role of rat CD8+CD45RClow $\mathrm{T}$ cells in experimental autoimmune uveitis (EAU). J Neuroimmunol. 2007;183(1-2):81-88.

77. Peng Y, et al. Minimally activated CD8 autoreactive $T$ cells specific for IRBP express a high level of Foxp3 and are functionally suppressive. Invest $O p h$ - 
thalmol Vis Sci. 2007;48(5):2178-2184.

78. Luger D, Caspi RR. New perspectives on effector mechanisms in uveitis. Semin Immunopathol. 2008;30(2):135-143.

79. Amadi-Obi A, et al. TH17 cells contribute to uveitis and scleritis and are expanded by IL- 2 and inhibited by IL-27/STAT1. Nat Med. 2007;13(6):711-718.

80. Luger D, et al. Either a Th17 or a Th1 effector response can drive autoimmunity: conditions of disease induction affect dominant effector category. J Exp Med. 2008;205(4):799-810.

81. Caspi RR, et al. Endogenous systemic IFN-gamma has a protective role against ocular autoimmunity in mice. J Immunol. 1994;152(2):890-899.

82. Damsker JM, Hansen AM, Caspi RR. Th1 and Th17 cells: Adversaries and collaborators. Ann N Y Acad Sci. 2010;1183:211-221.

83. Tang J, Zhu W, Silver PB, Su SB, Chan CC, Caspi RR. Autoimmune uveitis elicited with antigenpulsed dendritic cells has a distinct clinical signature and is driven by unique effector mechanisms: initial encounter with autoantigen defines disease phenotype. J Immunol. 2007;178(9):5578-5587.

84. Zhao C, et al. S-antigen specific T helper type 1 response is present in Behcet's disease. Mol Vis. 2008; $14: 1456-1464$.

85. Chi W, et al. IL-23 promotes CD4+ T cells to produce IL-17 in Vogt-Koyanagi-Harada disease.J Allergy Clin Immunol. 2007;119(5):1218-1224.

86. Chi W, et al. Upregulated IL-23 and IL-17 in Behcet patients with active uveitis. Invest Ophthalmol Vis Sci. 2008;49(7):3058-3064.

87. Ooi KG, Galatowicz G, Calder VL, Lightman SL. Cytokines and chemokines in uveitis: is there a correlation with clinical phenotype? Clin Med Res. 2006; 4(4):294-309.

88. Vanderlugt CL, Miller SD. Epitope spreading in immune-mediated diseases: implications for immunotherapy. Nat Rev Immunol. 2002;2(2):85-95.

89. Nussenblatt RB, Dinning WJ, Fujikawa LS, Chan $\mathrm{CC}$, Palestine AG. Local cyclosporine therapy for experimental autoimmune uveitis in rats. Arch Ophthalmol. 1985;103(10):1559-1562.

90. Dick AD, Forrester JV, Liversidge J, Cope AP. The role of tumour necrosis factor (TNF-alpha) in experimental autoimmune uveoretinitis (EAU). Prog Retin Eye Res. 2004;23(6):617-637.

91. Sharma SM, Nestel AR, Lee RW, Dick AD. Clinical review: Anti-TNFalpha therapies in uveitis: perspective on 5 years of clinical experience. Ocul Immunol Inflamm. 2009;17(6):403-414.

92. Imrie FR, Dick AD. Biologics in the treatment of uveitis. Curr Opin Ophthalmol. 2007;18(6):481-486.
93. Liang W, et al. B-cell delivered gene transfer of human S-Ag-Ig fusion protein protects from experimental autoimmune uveitis. Clin Immunol. 2006;118(1):35-41.

94. Martin AP, et al. Administration of a peptide inhibitor of alpha4-integrin inhibits the development of experimental autoimmune uveitis. Invest Ophthalmol Vis Sci. 2005;46(6):2056-2063.

95. Honey K. The comeback kid: TYSABRI now FDA approved for Crohn disease. J Clin Invest. 2008; 118(3):825-826.

96. Whitcup SM, DeBarge LR, Caspi RR, Harning R, Nussenblatt RB, Chan CC. Monoclonal antibodies against ICAM-1 (CD54) and LFA-1 (CD11a/CD18) inhibit experimental autoimmune uveitis. Clin Immunol Immunopathol. 1993;67(2):143-150.

97. Xu H, Manivannan A, Liversidge J, Sharp PF, Forrester JV, Crane IJ. Involvement of CD44 in leukocyte trafficking at the blood-retinal barrier. J Leukoc Biol. 2002;72(6):1133-1141.

98. Crane IJ, et al. Involvement of CCR5 in the passage of Th1-type cells across the blood-retina barrier in experimental autoimmune uveitis. J Leukoc Biol. 2006;79(3):435-443.

99. Caspi RR. Immunotherapy of autoimmunity and cancer: the penalty for success. Nat Rev Immunol. 2008;8(12):970-976.

100.Martin TM, Doyle TM, Smith JR, Dinulescu D, Rust K, Rosenbaum JT. Uveitis in patients with sarcoidosis is not associated with mutations in NOD2 (CARD15). Am J Ophthalmol. 2003;136(5):933-935.

101. Borzutzky A, Fried A, Chou J, Bonilla FA, Kim S, Dedeoglu F. NOD2-associated diseases: Bridging innate immunity and autoinflammation. Clin Immunol. 2010;134(3):251-261.

102. Wildner G, Diedrichs-Mohring M, Thurau SR. Induction of arthritis and uveitis in Lewis rats by antigenic mimicry of peptides from HLA-B27 and cytokeratin. Eur Immunol. 2002;32(1):299-306.

103. Ebringer A, Rashid T. B27 disease is a new autoimmune disease that affects millions of people. Ann NY Acad Sci. 2007;1110:112-120.

104.Nussenblatt RB, Kuwabara T, de Monasterio FM, Wacker WB. S-antigen uveitis in primates. A new model for human disease. Arch Ophthalmol. 1981; 99(6):1090-1092.

105. Fujino $Y$, et al. Immunopathology of experimental autoimmune uveoretinitis in primates. Autoimmunity. 1992;13(4):303-309.

106. Gregerson DS, Torseth JW, McPherson SW, Roberts JP, Shinohara T, Zack DJ. Retinal expression of a neo-self antigen, beta-galactosidase, is not tolerogenic and creates a target for autoimmune uveoreti- nitis. JImmunol. 1999;163(2):1073-1080.

107. Terrada C, et al. Regulatory $\mathrm{T}$ cells control uveoretinitis induced by pathogenic Th 1 cells reacting to a specific retinal neoantigen. J Immunol. 2006; 176(12):7171-7179.

108.Ichikawa T, et al. Spontaneous development of autoimmune uveoretinitis in nude mice following reconstitution with embryonic rat thymus. Clin Exp Immunol. 1991;86(1):112-117.

109.LeHoang P, et al. HLA-A29.2 subtype associated with birdshot retinochoroidopathy. Am J Ophthalmol. 1992;113(1):33-35.

110.Baarsma GS, Priem HA, Kijlstra A. Association of birdshot retinochoroidopathy and HLA-A29 antigen. Curr Eye Res. 1990;9(suppl):63-68.

111. Kilmartin DJ, Finch A, Acheson RW. Primary association of HLA-B51 with Behcet's disease in Ireland. BrJ Ophthalmol. 1997;81(8):649-653.

112. Mizuki N, Inoko H, Tanaka H, Kera J, Tsuiji K, Ohno S. Human leukocyte antigen serologic and DNA typing of Behcet's disease and its primary association with B51. Invest Ophthalmol Vis Sci. 1992;33(12):3332-3340

113. Arber N, Klein T, Meiner Z, Pras E, Weinberger A. Close association of HLA-B51 and B52 in Israeli patients with Behcet's syndrome. Ann Rheum Dis. 1991;50(6):351-353.

114.Jaakkola E, et al. Finnish HLA studies confirm the increased risk conferred by HLA-B27 homozygosity in ankylosing spondylitis. Ann Rheum Dis. 2006; 65(6):775-780.

115. Brewerton DA. The genetics of acute anterior uveitis. Trans Ophthalmol Soc U K. 1985;104(pt 3):248-249.

116. Numaga J, Islam MS, Mitsui H, Maeda H. [Anterior uveitis with ankylosing spondylitis and HLA]. Nippon Ganka Gakkai Zasshi. 1996;100(4):292-295.

117. Shindo Y, Ohno S, Yamamoto T, Nakamura S, Inoko H. Complete association of the HLA-DRB ${ }^{*} 04$ and -DQB1*04 alleles with Vogt-Koyanagi-Harada's disease. Hum Immunol. 1994;39(3):169-176.

118. Kim MH, et al. Association of HLA with Vogt-Koyanagi-Harada syndrome in Koreans. Am J Ophthalmol. 2000;129(2):173-177.

119. Kilmartin DJ, et al. Immunogenetics and clinical phenotype of sympathetic ophthalmia in British and Irish patients. Br J Ophthalmol. 2001;85(3):281-286.

120. Shindo Y, et al. Immunogenetic study of sympathetic ophthalmia. Tissue Antigens. 1997;49(2):111-115.

121. Oruc S, Duffy BF, Mohanakumar T, Kaplan HJ. The association of HLA class II with pars planitis. Am J Ophthalmol. 2001;131(5):657-659.

122.Cuccia Belvedere $\mathrm{M}$, et al. Genetic heterogeneity in uveitis. Dis Markers. 1986;4(3):243-246. 